Fordham University

Fordham Research Commons

\title{
E-advocacy in Human Services: The Impact of Organizational Conditions and Characteristics on Electronic Advocacy Activities among Nonprofits
}

Lauri Goldkind

Fordham University

Follow this and additional works at: https://research.library.fordham.edu/gss_facultypubs

Part of the Public Administration Commons, Public Policy Commons, Social Justice Commons, Social Policy Commons, and the Social Work Commons

\section{Recommended Citation}

Goldkind, Lauri, "E-advocacy in Human Services: The Impact of Organizational Conditions and Characteristics on Electronic Advocacy Activities among Nonprofits" (2014). Social Service Faculty Publications. 17.

https://research.library.fordham.edu/gss_facultypubs/17

This Article is brought to you for free and open access by the Graduate School of Social Service at Fordham Research Commons. It has been accepted for inclusion in Social Service Faculty Publications by an authorized administrator of Fordham Research Commons. For more information, please contact considine@fordham.edu, bkilee@fordham.edu. 
This article was downloaded by: [Lauri Goldkind]

On: 12 February 2015, At: 10:54

Publisher: Routledge

Informa Ltd Registered in England and Wales Registered Number: 1072954 Registered office: Mortimer House, 37-41 Mortimer Street, London W1T 3J H, UK

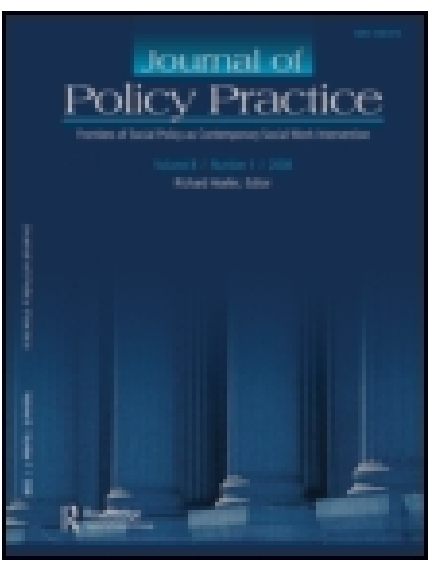

CrossMark
J ournal of Policy Practice

Publication details, including instructions for authors and subscription information:

http:// www.tandfonline.com/loi/ wjpp20

E-advocacy in Human Services: The Impact of Organizational Conditions and Characteristics on Electronic Advocacy Activities among Nonprofits

\author{
Lauri Goldkind ${ }^{a}$ \\ ${ }^{a}$ Graduate School of Social Service, Fordham University, New York, \\ New York, USA \\ Published online: 27 Aug 2014.
}

Click for updates

To cite this article: Lauri Goldkind (2014) E-advocacy in Human Services: The Impact of Organizational Conditions and Characteristics on Electronic Advocacy Activities among Nonprofits, J ournal of Policy Practice, 13:4, 300-315, DOI: 10.1080/ 15588742.2014.929073

To link to this article: http:// dx. doi.org/ 10.1080/ 15588742.2014.929073

\section{PLEASE SCROLL DOWN FOR ARTICLE}

Taylor \& Francis makes every effort to ensure the accuracy of all the information (the "Content") contained in the publications on our platform. However, Taylor \& Francis, our agents, and our licensors make no representations or warranties whatsoever as to the accuracy, completeness, or suitability for any purpose of the Content. Any opinions and views expressed in this publication are the opinions and views of the authors, and are not the views of or endorsed by Taylor \& Francis. The accuracy of the Content should not be relied upon and should be independently verified with primary sources of information. Taylor and Francis shall not be liable for any losses, actions, claims, proceedings, demands, costs, expenses, damages, and other liabilities whatsoever or howsoever caused arising directly or indirectly in connection with, in relation to or arising out of the use of the Content.

This article may be used for research, teaching, and private study purposes. Any substantial or systematic reproduction, redistribution, reselling, loan, sub-licensing, systematic supply, or distribution in any form to anyone is expressly forbidden. Terms \& Conditions of access and use can be found at http://www.tandfonline.com/page/termsand-conditions 


\title{
E-advocacy in Human Services: The Impact of Organizational Conditions and Characteristics on Electronic Advocacy Activities among Nonprofits
}

\author{
LAURI GOLDKIND \\ Graduate School of Social Service, Fordham University, New York, New York, USA
}

\begin{abstract}
E-advocacy, or the constellation of electronic tools used for policy advocacy, offer cost-effective approaches for engaging constituents to create social change. Providers of human services may face challenges when trying to implement these tools. While many electronic tools have low barriers for entry, other factors may inhibit their use in agencies. This article explores the organizational characteristics related to the use of electronic advocacy strategies. Based on a survey of nonprofit executives, the study uses path modeling to describe the connections between organizational characteristics and the use of electronic advocacy tools. Implications of these findings are discussed.
\end{abstract}

KEYWORDS E-advocacy, electronic advocacy, organizational characteristics, policy advocacy, social change, social media

\section{INTRODUCTION}

Over the past decade, a sea change in electronic and social media occurred, which continues to bring sweeping transformation to advocacy practice around the world. As recently as five years ago, an organization interested in policy change might have placed a staff /volunteer canvasser on the street who would stop a possible constituent, engage him or her in conversation about an issue, and secure a signature. Now, with online petitions posted on Facebook, re-tweeted on Twitter, and remarked upon on Tumblr,

Address correspondence to Lauri Goldkind, Graduate School of Social Service, Fordham University, 113 West 60th Street, New York, 10023 United States. E-mail: goldkind@ fordham.edu 
there is the potential to collect thousands of signatures in a matter of hours. Combine these electronic strategies with the technology challenges currently faced by human service organizations (HSO) and we can imagine a scenario where nonprofit human service providers are playing catch-up in the electronic advocacy arena (Le Dantec \& Edwards, 2008; Salamon, 2002). These HSOs are not only constrained by their traditional focus on direct service and reticence to be accused of lobbying, but are also hampered by a lack of technology infrastructure and the knowledge as to how to effectively mobilize their constituents and advocate electronically on their behalf.

Historically, nonprofit HSOs have been slow to adapt to technological change and innovations (Corder, 2001, Dunlop \& Fawcett, 2008, Edwards \& Hoefer, 2010; Merkel et al., 2007). Yet increasingly organizational survival depends on a leader's ability to adapt to changing organizational contexts, increased competition for scarce resources, and evolving technological strategies (Hackler \& Saxton, 2007). In addition, advocacy and social change practice have rapidly become linked with technology tools and Internet-based outreach (McNutt, 2008; McNutt \& Boland, 1999). This study explores the relationships between organizational characteristics, organizations' advocacy orientation, and their use of electronic advocacy strategies.

\section{LITERATURE REVIEW}

Advocating for disenfranchised groups, empowering constituents, and working on behalf of social justice are considered imperitives of the human services sector (Berry, 2005, Schachter, 2011). Yet the level of policy advocacy engagement by nonprofit human service providers has been found to be relatively modest (Almog-Bar \& Schmid, 2013; Berry, 2005; Kimberlin, 2010; MacIndoe \& Whalen, 2013; Saloman \& Geller, 2008). Many factors, including limited resources and knowledge, a fear of reprisal from funders, and misconceptions of the legal limitations placed on nonprofit 501c(3) organizations, contribute to the less than robust advocacy activities of the sector (Almog-Bar \& Schmid, 2013; Salamon \& Anheier, 1992).

Electronic, Internet-based interactive tools (e.g., social media) are facilitating the increased ease through which individuals and organizations can engage in advocacy campaigns (Guo \& Saxton, 2012; Nah \& Saxton, 2013). Some literature discusses the types and goals of various advocacy activities undertaken by HSOs, and there is general agreement that the nonprofit human services sector is uniquely positioned to uphold a civil society through advocacy activities. However, much remains to be understood about how and under what conditions agencies adopt the use of electronic advocacy tools (Berry \& Arons, 2003; Donaldson, 2007, Hoefer, 2001). 


\section{Electronic Advocacy Practices in Nonprofit Organizations}

The Internet and social media are revolutionizing the way that the nonprofit sector does business. From online fundraising, to managing data in cloud-based warehouses, to using Twitter and text messaging to mobilize constituents, technology and the tools that have emerged to apply it are changing the practice landscape of human services organizations. In addition, electronic advocacy, defined as "the use of technologically intensive media as a means to influence stakeholders to effect policy change" (Fitzgerald \& McNutt, 1997, p. 3), which is driven by social media tools are revolutionizing policy advocacy practices in the United States and around the world. Proliferating rapidly, these strategies and tools cannot be ignored by nonprofit leaders who wish to remain relevant in increasingly competitive climates.

\section{Facilitators of Advocacy Practice}

Organizations and the individuals that function within them require structures and supports to meet their goals. The growth and maintenance of an organizational advocacy program, and the ability to meet advocacy objectives, is no exception. Among the factors found to facilitate the achievement of organizational advocacy goals are coalition membership and leadership support, including board support, and resources (Donaldson, 2007).

Not surprisingly, organizations with greater capacity in terms of staff, dollars, and volunteers are more likely to engage in advocacy behaviors than organizations with fewer such resources (Berry \& Arons, 2003, Suarez, 2009). Gibelman and Kraft (1996) identify agency size, mission, functions and staff expertise as the characteristics that determine the nature of an agency's advocacy practice.

Organizational leadership may be one of the key factors that influence an agency's advocacy activities. Gibleman \& Kraft (1996), Salamon (1995), Saidel \& Harlan (1998), and DeVita, Montilla, Reid, \& Fatiregun (2004) all suggest that leadership and the leaders' orientation, vision, and commitment to advocacy are critical factors in organization's advocacy engagement.

\section{BARRIERS TO ADVOCACY PRACTICE}

As mentioned previously, the nonprofit sector is thought to be uniquely situated to participate in civic engagement activities. For human services providers specifically, and especially for those with missions oriented toward empowering the disenfranchised and marginalized, advocacy would seem like a natural complement to other organizational services and activities 
(Smith \& Pekkanen, 2012). However, organizational barriers exist that inhibit human services providers to fully catalyze their advocacy activities.

Time, expertise, and resources are the most frequently mentioned barriers that prohibit agencies from devoting themselves to advocacy activities (Donaldson, 2007; McNutt \& Boland, 1999). Given the emphasis on advocacy as a singular feature of the sector, it's noteworthy that a significant number of organizational leaders do not feel like they are competent to engage in advocacy activities. And as agencies are pressured to demonstrate effectiveness and efficiency with ever shrinking resources, advocacy and civic engagement are among those activities that appear to be considered non-essential.

A lack of resources and a lack of expertise are also noted as the most frequent barriers to the use of E-advocacy specifically (McNutt \& Boland, 1999). McNutt (2008) goes further, and suggests that similar to the Digital Divide discussed in the early 2000s there is an emergent Organizational Digital divide that threatens to leave small, less capitalized organizations behind due both to a lack of access to technology tools and the human capital to deploy them.

\section{CONCEPTUAL FRAMEWORK AND HYPOTHESES}

The purpose of this study is to explore the organizational attributes that promote the use of electronic advocacy strategies. This model uses two demographic characteristics: organizational age and budget size and two additional dimensions, organizational structures and advocacy climate to explain engagement in advocacy activities. This study is based in part on earlier work of MacIndoe and Whalen (2013), as well as Donaldson (2007) all of whom sought to explore the organizational correlates of advocacy behavior. Each of the seven hypothesis described as follows focuses on a different organizational attribute. The first two hypotheses deal with organization's age and budget size on an organization's engagement with advocacy activities. The second two hypotheses focus on structural and cultural elements of the organization, which may influence an organization's engagement with policy advocacy activities. Figure 1 depicts a path model that identifies these factors and the linkages that connect them. These linkages represent the hypotheses that this study seeks to test. Taken together, these hypotheses seek to explain the organizational characteristics that impact a human service agency's use of electronic advocacy strategies.

\section{Organizational Demographics}

Scholars of nonprofit organization's engagement in advocacy activities have found that characteristics such as agency size, age and mission influence advocacy behaviors (Gibleman \& Kraft, 1996; MacIndoe \& Whalen, 2013). Organizations with larger budgets and resources are more likely to engage in 


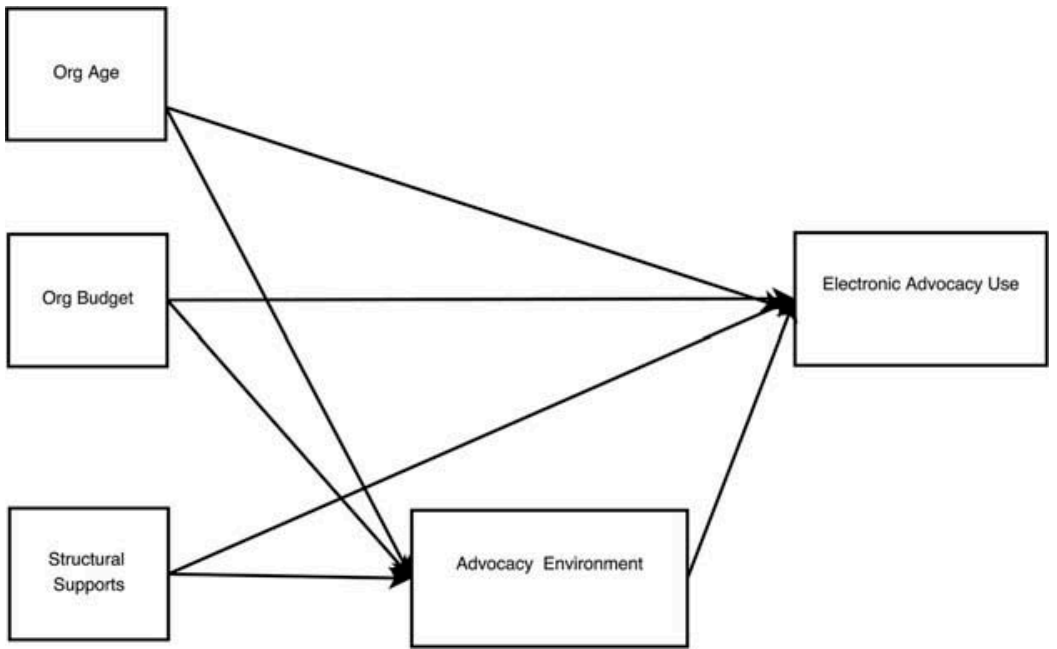

FIGURE 1 Conceptual model.

policy advocacy (Berry \& Arons, 2003; Child \& Grønbjerg, 2007; Donaldson, 2007). Minkoff (1998) also finds a positive correlation between the number of staff and advocacy and found that older, more established agencies had the stability and legitimacy to take on the risks inherent in engaging in policy advocacy.

Hypothesis 1: The age or "tenure" of the organization is expected to have an inverse effect on electronic advocacy use.

Hypothesis 2: The age or "tenure" of the organization is expected to have a mediated effect on electronic advocacy use through the advocacy environment.

Hypothesis 3: The size of the organization's budget is hypothesized to have a direct effect on electronic advocacy use.

Hypothesis 4: The size of the organization's budget is hypothesized to have an indirect effect on electronic advocacy use through the advocacy environment.

\section{Organization's Structural and Cultural Dimensions}

As the literature on nonprofit advocacy has evolved, so too has the notion that organizations must have institutional structures to support advocacy work (Netting, O'Connor, \& Fauri, 2007; Taylor, 1991). Taylor (1991) argues that all the constituents of an organization including board members, staff and community members must be engaged in order for advocacy work to succeed. Netting et al. (2007)suggest that beyond buy-in from 
board and staff, specific skills are required to carry out advocacy program goals.

Hypothesis 5: Structural supports, defined as those organizational mechanisms designed to facilitate advocacy, is hypothesized to have a direct effect on electronic advocacy use.

Hypothesis 6: Structural supports, defined as those organizational mechanisms designed to facilitate advocacy, is hypothesized to have an indirect effect on electronic advocacy use through the advocacy environment.

Advocacy climate is one area that has not been widely examined in the literature. Advocacy climate or advocacy culture speaks to how the engagement in social justice and policy advocacy work is woven into the fabric of the organization's culture and values. One example of this is organizations' participation in coalitions with other organizations (Mellinger, 2014). Bass, Arons, Guinane, and Carter (2007) found that memberships and collaborations with like-minded organizations increased advocacy involvement.

Hypothesis 7: The electronic advocacy environment, defined as those organizational characteristics which support and enhance advocacy activities, is expected to have a direct effect on electronic advocacy use.

\section{METHODS}

A mail-back survey, designed to reach a national sample of human services executives, was used to collect data for this study. A cover letter and paper survey instrument was mailed to 3,800 executive directors of category P20 human services providers as identified by the National Taxonomy of Exempt Entities (NTEE). The NTEE system is used by the IRS and the National Center for Charitable Statistics (NCCS) to classify nonprofit organizations (Blackwood, Roeger, \& Pettijohn, 2012), and all organizations with an NTEE code of P (Human Services) with budgets greater than $\$ 30,000$ per year were included in the study population. Following the initial mailing, four followup reminder postcards were sent in an attempt to increase the response rate. Anonymous surveys were returned in postage paid envelopes; agency leaders did not submit their names or the names of their organizations.

The cover letter to agency executives invited them to participate in a study exploring the use of social media for meeting advocacy goals. The letter also introduced the principal investigator as a current faculty member with a personal interest in this subject matter, and laid out the objectives of 
the study for the prospective participants. This research was conducted with Institutional Review Board approval from the authors' university.

\section{Sample}

A total of 264 completed surveys were returned. Despite employing tactics to increase response rate suggested by Dillman (2000) and others the response rate was 7\%. Hager, Wilson, Pollak, and Rooney (2003) suggest that surveys of organizations frequently receive lower return rates than surveys of individuals, with $15 \%$ return rates sometimes reaching a level of acceptability for organizational surveys.

\section{Instrument}

Organizational Age and Budget. The survey instrument included eight questions describing organizational demographic characteristics including questions about agency age and agency budget size.

Barriers and Facilitators of Electronic Advocacy. The survey instrument included 11 items that requested the respondents to characterize the degree to which various structural characteristics of the organization served as a barrier to or a facilitator of the use of electronic advocacy. For example, "structural characteristics" included board support, financial support, technology infrastructure, and senior leadership support among others (see Table 1).

Electronic Advocacy Use. This study adapted the McNutt's Child Welfare Electronic Advocacy Survey instrument, in order to capture agency's adoption of e-advocacy strategies and engagement with electronic policy advocacy activities. The survey focuses on the broad range of social media and Internet tools that organizations can use for pursuing advocacy goals.

The participants in the study were asked to describe their "level" of use of an array of 27 electronic advocacy strategies including social media tools

TABLE 1 Barriers and Facilitators of Electronic Advocacy

\begin{tabular}{llll}
\hline & $n$ & $\bar{x}$ & SD \\
\hline Board Support & 202 & 2.37 & 2.31 \\
Fiscal Support & 202 & 1.32 & 2.86 \\
Technology Infrastructure & 202 & 1.20 & 2.48 \\
Senior Executive Support & 202 & 2.88 & 2.16 \\
Technology Champions & 202 & 0.99 & 2.52 \\
Coalition Membership & 202 & 2.08 & 2.22 \\
Advocacy Core Activity & 202 & 1.36 & 2.73 \\
Universal Access & 202 & 0.84 & 2.44 \\
Space & 202 & 0.72 & 2.53 \\
Resistance & 202 & 0.07 & 2.03 \\
Expertise & 202 & 2.00 & 2.52 \\
\hline
\end{tabular}


(e.g., Facebook, blogs, and podcasting) as well as direct electronic communication tools such as e-mail, chat rooms, and listservs. Specifically, the participants were asked to indicate whether they did not use each strategy at all, sometimes, or regularly.

\section{Data Reduction}

The 11 items measuring the Barriers and Facilitators of Electronic Advocacy use were submitted to a principal axis factor analysis using a promax rotation. Included as part of the output from the factor analysis are two indices of the "factorability" of the 11 "barriers/facilitators" items, i.e., the KaiserMeyer-Olkin (KMO) measure of sampling adequacy and the Bartlett's test of sphericity. These criteria exceed the commonly recommended criterion that a set of items to be factored have a KMO value of at least .60, i.e., for these 11 items the KMO value is .85, indicating a substantial amount of shared variance in them. In addition, Bartlett's test of sphericity, which tests the null hypothesis that the correlation matrix is an "identity matrix," meaning that the correlations among these items are zero, is also rejected $\left(\chi^{2}=750.64\right.$ (55), $p<.001$ ). Taken together, these two findings indicate that the 11 barriers and facilities items are, in fact, factorable.

Visual inspection of the scree plot from the factor analysis indicated that a two-factor solution adequately summarized the "structure" in this set of 11 items. The associated "pattern matrix" from this two-factor solution is presented in Table 2. As seen in this table, the seven items loading on the first factor, taken together, appear to measure the sources of "structural support" for electronic advocacy activities in these organizations. The second factor, comprised of four items, measures the "advocacy orientation" of these organizations.

Internal consistency reliability analyses of the items comprising each factor finds that both measure are, in fact, reliable, i.e., the "Structural Support"

TABLE 2 Factor Loadings

\begin{tabular}{lcc}
\hline & $\begin{array}{c}\text { Structural } \\
\text { Support }\end{array}$ & $\begin{array}{c}\text { Advocacy } \\
\text { Environment }\end{array}$ \\
\hline Board Support & .77 & \\
Fiscal Support & .71 & \\
Technology Infrastructure & .54 & \\
Senior Executive Support & .52 & .27 \\
Expertise & .49 & .97 \\
Technology Champions & .46 & .90 \\
Resistance & .32 & .71 \\
Universal Access & & .51 \\
Advocacy Core Activity & & .43 \\
Coalition Membership & & .43 \\
Space & & \\
\hline
\end{tabular}


factor's reliability coefficient is (Cronbach's $\alpha=$ ) .80 and the "Advocacy Orientation" factor's reliability is (Cronbach's $\alpha=$ ) .78 .

\section{RESULTS}

\section{Organizational Age and Budget}

Participating organizations ranged in age from 4 to 155 years old with a mean of 36 years and a median of 25 years. On average, organizations budgets were $\$ 500,000$, with a range of less than $\$ 50,000$ (9\%) to over $\$ 5,000,000$ (27\%). Sixty three percent of respondents report having an individual who is responsible for coordinating technology on their staff. In addition, 66\% reported having memberships in coalitions or other affinity group organizations. A majority of the respondents (87\%) report spending $25 \%$ or less of their organization's time engaged in advocacy activities.

\section{Structural Supports}

Structural supports is comprised of seven variables. These supports included board support, fiscal support, technology infrastructure, expertise as well as a technology champion. Factor loadings may be found in Table 2.

\section{Advocacy Environment}

Advocacy environment is comprised of four variables. These variables included advocacy activities and coalition members. Factor loadings for these variables may be found in Table 2 .

\section{Electronic Advocacy Use}

The descriptive statistics for these variables are presented in Table 3. Note that in this table, the percentage of the organization sample using each strategy at least "sometimes" is reported as the percent of organizations using this strategy (in the column labeled, \%). As seen in this table, the most widely used electronic strategies are e-mails to decision-makers (56\%) and using e-mail internally to coordinate policy advocacy efforts (52\%). With respect to the social media advocacy strategies, the most prevalent was the use of social networking (e.g., LinkedIn and Facebook; 49\%). All of the remaining social media advocacy strategies are much less utilized. Finally, with regard to "other" electronic strategies, the most widely used are online fundraising (30\%) and instant messaging (30\%), followed by online volunteer recruiting (26\%) and online mapping (22\%). 
TABLE 3 Percent of Agencies Using Electronic Advocacy Tools and Techniques at Least Sometimes

\begin{tabular}{|c|c|c|}
\hline Strategy Type & $n$ & $\%$ \\
\hline \multicolumn{3}{|l|}{ Electronic Advocacy Strategy } \\
\hline $\begin{array}{l}\text { E-mail to Coordinate Policy Influence Efforts within } \\
\text { organization }\end{array}$ & 258 & .52 \\
\hline $\begin{array}{l}\text { E-mail to Coordinate Policy Influence Efforts outside of } \\
\text { organization }\end{array}$ & 258 & .43 \\
\hline Electronic Mail Discussion List About Policy Issues (List serve) & 256 & .27 \\
\hline Electronic Mail [E-Mail] to Decision Makers & 259 & .56 \\
\hline Newsgroups & 258 & .16 \\
\hline Distribution Lists [Mass E-Mail Distribution] & 258 & .45 \\
\hline Chat Rooms & 257 & .00 \\
\hline \multicolumn{3}{|l|}{ Social Media Advocacy Strategy } \\
\hline Blogs & 258 & .11 \\
\hline RSS Feeds (Really Simple Syndication) & 252 & .03 \\
\hline Wikis (Wikipedia) & 257 & .07 \\
\hline Photo Sharing (Picassa, Flicker) & 255 & .11 \\
\hline Podcasting & 255 & .02 \\
\hline Video Sharing (YouTube) & 259 & .14 \\
\hline Micro blogging (Twitter) & 257 & .15 \\
\hline Social Networking (LinkedIn, Facebook, etc.) & 259 & .49 \\
\hline Social Bookmarking (Delicious, Digg, StumbleUpon, etc.) & 255 & .01 \\
\hline \multicolumn{3}{|l|}{ Other Electronic Strategy } \\
\hline $\begin{array}{l}\text { Online Fund Raising (secure donation sites or shop for a } \\
\text { cause sites) }\end{array}$ & 259 & .30 \\
\hline Video-Teleconferencing & 259 & .12 \\
\hline Online Survey Research & 259 & .19 \\
\hline Online Volunteer Recruiting & 260 & .26 \\
\hline Online Mapping (like Google Earth or Google Maps) & 257 & .22 \\
\hline $\begin{array}{l}\text { Secure Intranet for Coordinating Activities private } \\
\text { communication }\end{array}$ & 259 & .22 \\
\hline Meet ups [a tool that helps to organize face-to-face meetings] & 256 & .09 \\
\hline Instant Messaging, Texting and Short Message Systems & 260 & .30 \\
\hline Virtual Reality Simulation [like Second Life] & 256 & .08 \\
\hline Online Petitions & 257 & .04 \\
\hline Web-based Conferencing & 260 & .17 \\
\hline
\end{tabular}

\section{Understanding Electronic Advocacy Use}

The inter-correlations between the independent, mediating, and dependent variables presented in this article are reported in Table 4. As can be seen in the table, organizational age and organization's budget was found to be significantly correlated $(r=.56 ; p .>.00)$. Similarly Advocacy Orientation and Electronic Advocacy Use were found to be positively and significantly correlated $(r=.43$; p. $>.00)$.

The recursive path model derived from these inter-correlations and presented in Figure 2 was estimated in MPLUS 7.0 using maximum likelihood estimation. Because the model is recursive, it will fit the data exactly by 
TABLE 4 Variables Inter-correlations and Means (Standard Deviations)

\begin{tabular}{|c|c|c|c|c|c|}
\hline Variables & 1 & 2 & 3 & 4 & 5 \\
\hline 1. Org Age & - & & & & \\
\hline 2. Budget & $.56^{*}$ & - & & & \\
\hline 3. Structural Support & .15 & .18 & - & & \\
\hline 4. Advocacy Orientation & .10 & .19 & $.59^{*}$ & - & \\
\hline 5. Electronic Advocacy Use & .07 & $.31^{*}$ & $.33^{*}$ & $.43^{*}$ & - \\
\hline
\end{tabular}

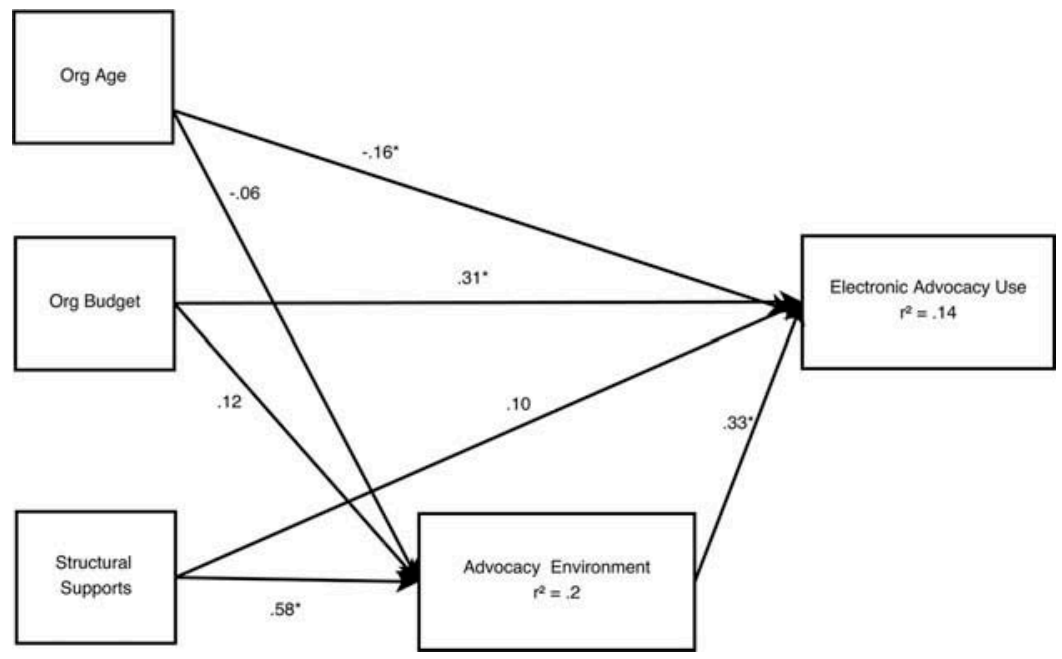

FIGURE 2 Path model.

mathematical construction. That is to say, conventional model fit indices such as the model chi-square statistic, the Comparative Fit Index, and the Root Mean Square Error of Approximation are not germane to this type of model.

As seen in Figure 2, and consistent with Hypothesis 1, the age or tenure of the organization does have a statistically significant, modest negative effect on electronic advocacy use; the age of the organization is inversely, albeit significantly, related to the use of electronic advocacy strategies. $(\beta=$ $-.16, p<.05)$. However, Hypothesis 2, regarding the indirect effect via the endogenous mediator, the advocacy environment, is not statistically significant (standardized indirect effect (i.e.) $=-.02, p>.05$ ).

With respect to Hypothesis 3, and consistent with expectation, the size of the budget is positively and significantly related to the use of electronic advocacy strategies; organizations with more financial resources or capacity are the ones with greater levels of engagement in electronic advocacy strategies. $(\beta=.31, p<.05)$. However, hypothesis 4 , testing the indirect effect via the endogenous mediator, i.e., the advocacy environment, is not statistically significant (standardized indirect effect (i.e.) $=.04, p>.05$ ) 
Hypothesis 5 presents a different pattern of statistically significant findings. Contrary to expectations, the direct effect of organizational structure on the use of electronic advocacy strategies is not statistically significant $(\beta=$ $.10, p>.05)$. Yet, as expected hypothesis 6 , testing the indirect effect via the advocacy environment is significant (standardized indirect effect $=.19$, $p<.05$ )

Finally, with respect to Hypothesis 7, the direct effect of the advocacy environment on electronic advocacy strategies is, as hypothesized, positive, moderately strong, and statistically significant $(\beta=.33, p<.05)$.

\section{DISCUSSION}

With respect to the first two hypothesis, the findings support the claim that older organizations are somewhat less involved in adopting electronic advocacy strategies. More than likely this is a reflection of the fact that these organizations have been in existence for a long time and probably have systems in place that serve the same objectives as would the newer electronic advocacy strategies. Since these systems are currently functional they aren't easily or quickly replaced, and thus, the opportunity to embrace electronic advocacy strategies are hampered. Only when these new strategies are understood and their efficiency becomes evident will they be likely to be embraced by the oldest agencies. Hopefully, as more modern systems of advocacy infuse themselves into the workplace even organizations of longstanding will begin to embrace electronic advocacy.

While the direct effect of organizational age (Hypothesis 1) on the use of electronic strategies was supported in this investigation, the hypothesized indirect effect (Hypothesis 2) through the advocacy environment was not supported. The rationale for expecting a significant indirect effect via the advocacy environment is that organizations of longer standing have had more opportunity to develop the intra-organizational "infrastructure" (i.e., Internet capability, sufficient physical space) through which they could conduct their advocacy activities. These organizations are also more likely to have a web of organizational partners sharing a like-minded commitment to advocacy, which, in turn, could foster a greater commitment to electronic advocacy as mechanism for furthering those activities. Yet those organizations, because they are long-standing, may suffer from bureaucratization and territoriality both of which can thwart the adoption of new ways of conducting business like the use of electronic advocacy strategies. Taken together, these countervailing forces might render older organizations unable to integrate the opportunities that electronic advocacy strategies present since they pose a threat to long-standing, existing organizational arrangements; the benefits of electronic advocacy are offset, at least to some extent, by the threats to preexisting organizational arrangements. To the extent that this is true, the 
absence of a significant indirect effect between organizational tenure and the adoption of electronic advocacy strategies is, perhaps, less surprising.

With regard to the hypothesis three and four, human service organizations with greater financial resources are more likely to have the capacity to embrace change given that it confers exposure and efficiency to their advocacy activities. However, as stated above, greater resources don't necessarily imply the deployment of those resources in ways that would seem to advantage these organizations. The seeming benefits of change, to say nothing of financially underwriting of that change, is an expensive and difficult undertaking even when the advocacy environment for it exists.

As found in the results, hypothesis five, structural support did not have the expected direct effect on electronic advocacy use. Yet there was a strong indirect effect of structural support on electronic advocacy use through the advocacy environment. This finding indicates the "mechanism" by which greater structural support "pays off" in the use of electronic advocacy. More specifically, organizations with greater structural support for electronic advocacy use (e.g., the board's investment in these technologies, the presence of a technology "champion," financial resources) are typified by an "environment" or "culture" conducive to electronic advocacy which, in turn, "expresses" itself in a greater embrace of these newer technologies. The fact that the direct effect of structural support on the use of these newer technologies is statistically insignificant may simply reflect the fact the relationship between these two constructs is entirely indirect through the organization's "attitude" toward these newer technologies.

Finally, and as a logical corollary of the explanation for the indirect effect just outlined, it is the case that organizations' whose "cultures" are conducive to the adoption of these newer technologies are the ones that embrace them. Stated somewhat differently, organizations use electronic technologies in no small measure because their organizational cultures are, in fact, conducive to them.

\section{LIMITATIONS}

As a rapidly evolving area of inquiry, little is formally understood about how agencies are engaging electronic advocacy and social media strategies or how internal agency structures may be viewed as barriers or facilitators to such work. Part of what has made it difficult to learn about this topic is that it has only recently emerged. Because of this little exists in the way of survey instruments suitable for investigating this topic. While the survey instrument used in this study is not entirely new (several of the constructs operationalized in this study are derived from a survey instrument developed by other investigators of organizational "culture" and its role in understanding how organizations work) much of the instrument used in this study is new. As such, it's a beginning, but only a beginning in capturing the needed 
constructs to more fully explore the topic at hand. Other investigators may be able to enhance or otherwise improve upon this initial effort.

\section{CONCLUSIONS}

Certainly, e-advocacy is an area of interest for nonprofit leaders and scholars of the nonprofit world. More than ever, organizational success relies on organizations' capacities to engage their constituents and to communicate with them using social media tools. Most executive directors would agree that employing electronic technology strategies for policy advocacy and organizational sustainability campaigns are essential in today's world. However, little guidance exists to guide today's leaders about which strategies might be effective or how to implement and manage the use of electronic tools effectively. As the digital age advances these issues will become even more pressing as organizations strive to advance their agendas, maintain their organizations, and better serve their constituents.

\section{REFERENCES}

Almog-Bar, M., \& Schmid, H. (2013). Advocacy activities of nonprofit human service organizations: A critical review. Nonprofit and Voluntary Sector Quarterly 43(1), $11-35$.

Bass, G. D., Arons, D. F., Guinane, K., \& Carter, M. F. (2007). Seen but not heard: Strengthening nonprofit advocacy. Washington, DC: The Aspen Institute.

Berry, J. M. (2005). Nonprofits and civic engagement. Public Administration Review, 65, 568-578. doi:10.1111/j.1540-6210.2005.00484.x

Berry, J. M., \& Arons, D. F. (2003). A voice for nonprofits. Washington, DC: Brookings Institution.

Blackwood, A., Roeger, K., \& Pettijohn, S. (2012). The nonprofit almanac 2012. Washington, DC: Urban Institute.

Child, C. D., \& Grønbjerg, K. A. (2007). Nonprofit advocacy organizations: Their characteristics and activities. Social Science Quarterly, 88(1), 259-281.

Corder, K. (2001). Acquiring new technology: Comparing nonprofit and public sector agencies. Administration and Society, 33, 194-219.

DeVita, C., Montilla, M., Reid, B., \& Fatiregun, O. (2004). Organizational factors influencing advocacy for children. Washington, DC: Urban Institute Press.

Dillman, D. A. (2000). Mail and internet surveys: The tailored design method. New York, NY: John Wiley.

Donaldson, L. P. (2007). Advocacy by nonprofit human service agencies: Organizational factors as correlates to advocacy behavior. Journal of community Practice, 15(3), 139-158.

Dunlop, J. M., \& Fawcett, G. (2008). Technology-based approaches to social work and social justice. Journal of Policy Practice, 7(2-3), 140-154.

Edwards, H. R., \& Hoefer, R. (2010). Are social work advocacy groups using Web 2.0 effectively? Journal of Policy Practice, 9(3-4), 220-239. 
FitzGerald, E., \& McNutt, J. G. (1997, March). Electronic advocacy in policy practice: A framework for teaching technologically based practice. Paper presented the 1997 CSWE Annual Program Meeting, Chicago, IL.

Gibelman, M., \& Kraft, S. (1996). Advocacy as a core agency program: Planning considerations for voluntary human service agencies. Administration in Social Work, 20(4), 43-59.

Guo, C., \& Saxton, G. D. (2014). Tweeting social change: How social media are changing nonprofit advocacy. Nonprofit and Voluntary Sector Quarterly, 43(1), 57-79.

Hackler, D., \& Saxton, G. D. (2007). The strategic use of information technology by nonprofit organizations: Increasing capacity and untapped potential. Public Administration Review, 67(3), 474-487.

Hager, M. A., Wilson, S., Pollak, T. H., \& Rooney, P. M. (2003). Response rates for mail surveys of nonprofit organizations: A review and empirical test. Nonprofit and Voluntary Sector Quarterly, 32(2), 252-267.

Hoefer, R. (2001). Highly effective human services interest groups: Seven key practices. Journal of Community Practice, 9(2), 1-13.

Kimberlin, S. E. (2010). Advocacy by nonprofits: Roles and practices of core advocacy organizations and direct service agencies. Journal of Policy Practice, 9(3-4), 164-182.

Le Dantec, C. A., \& Edwards, W. K. (2008). The view from the trenches: Organization, power, and technology at two nonprofit homeless outreach centers. Proceedings of the 2008 ACM conference on Computer supported cooperative work (pp. 589-598). New York, NY: ACM.

MacIndoe, H., \& Whalen, R. (2013). Specialists, generalists, and policy advocacy by charitable nonprofit organizations. Journal of Sociology \& Social Welfare, 40(2), 119-149.

Mellinger, M. S. (2014). Beyond legislative advocacy: Exploring agency, legal, and community advocacy. Journal of Policy Practice, 13(1), 45-58.

Merkel, C., Farooq, U., Xiao, L., Ganoe, C., Rosson, M. B., \& Carroll, J. M. (2007). Managing technology use and learning in nonprofit community organizations: Methodological challenges and opportunities. Proceedings of the $2007 \mathrm{sym}$ posium on Computer human interaction for the management of information technology (Article 8). New York, NY: ACM. doi:10.1145/1234772.1234783

McNutt, J. (2008). Advocacy organizations and the organizational digital divide. Currents: Scholarship in the Human Services, 7(2), 1-13.

McNutt, J. G., \& Boland, K. M. (1999). Electronic advocacy by nonprofit organizations in social welfare policy. Nonprofit and Voluntary Sector Quarterly, 28(4), 432-451.

Minkoff, D. C. (1998, November 14). Organizational barriers to advocacy. Wye River, MD: Nonprofit Sector Research Fund Strategy Group.

Nah, S., \& Saxton, G. D. (2013). Modeling the adoption and use of social media by nonprofit organizations. New Media E Society, 15(2), 294-313.

Netting, F. E., O'Connor, M. K., \& Fauri, D. P. (2007). Planning transformative programs: Challenges for advocates in translating change processes into effective measures. Administration in Social Work, 31, 59-81. 
Quinn, R. E., \& Rohrbaugh, J. (1981). A competing values approach to organizational effectiveness. Public Productivity Review, 5, 122-140.

Saidel, J. R., \& Harlan, S. L. (1998). Contracting and patterns of nonprofit governance. Nonprofit Management and Leadership, 8(3), 243-259.

Salamon, L. M. (1995). Partners in public service: Government-nonprofit relations in the modern welfare state. Baltimore, MD: Johns Hopkins University Press.

Salamon, L. M. (Ed.). (2002). The state of nonprofit America. Washington, DC: Brookings Institution Press.

Salamon, L. M., \& Anheier, H. K. (1992). In search of the non-profit sector. I: The question of definitions. Voluntas: International Journal of Voluntary and Nonprofit Organizations, 3(2), 125-151.

Salamon, L. M., \& Geller, S. L. (2008). Nonprofit America: A force for democracy? (Communique No. 9). John Hopkins University, Center for Civil Society Studies. Baltimore, MD: John Hopkins University Press.

Schachter, H. L. (2011). Reflections on political engagement and voluntary association governance. Nonprofit and Voluntary Sector Quarterly, 40(4), 703-719.

Smith, S. R., \& Pekkanen, R. (2012). Revisiting advocacy by non-profit organizations. Voluntary Sector Review, 3(1), 35-49.

Suarez, D. F. (2009). Nonprofit advocacy and civic engagement on the Internet. Administration E Society, 41(3), 267-289.

Taylor, E. D. (1991). The role of structure in effective agency advocacy. Social Work with Groups, 14, 141-151. 